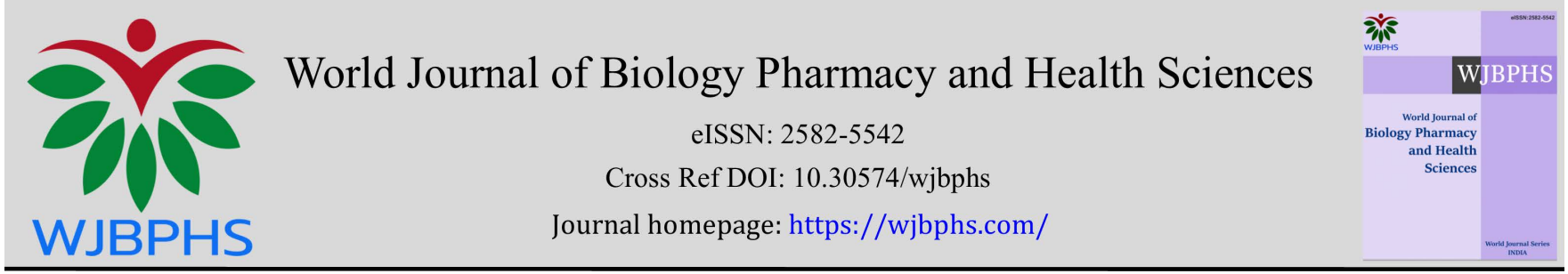

(CASE REPORT)

\title{
COVID -19: Case report of assertive treatment in diabetic patients
}

\author{
Glayson Guimarães Morais Ferreira * and Luciene dos Santos Ferreira Guimarães \\ Institute of Applied Naturopathy of Belo Horizonte, Mahatman Institute, Alagoas Street, 1314, Belo Horizonte, Minas Gerais, \\ Brazil.
}

World Journal of Biology Pharmacy and Health Sciences, 2021, 07(01), 009-014

Publication history: Received on 04 May 2021; revised on 10 June 2021; accepted on 13 June 2021

Article DOI: https://doi.org/10.30574/wjbphs.2021.7.1.0062

\begin{abstract}
COVID 19 is currently one of the most impacting factors in world society, both because of the ineffectiveness of pharmacological measures and because of socioeconomic inequality. Diabetes is one of the comorbidities that makes the body more vulnerable to the development of severe COVID-19. Diabetes does not increase the patient's risk of becoming infected with the new coronavirus, but it does increase the chances of complications from the infection. This study uses a descriptive and observational methodology of the assertive evolution of the COVID-19 case report. It is a descriptive, exploratory, non-invasive method, with mediated intervention, in a 42-year-old male patient, type 2 diabetic, undergoing pharmacological monitoring and in treatment of lichenoid pityriasis with 500mg tetracycline hydrochloride, on alternate days. During treatment for pityriasis lichenoid, the patient contracted the coronavirus, changing the antibiotic for daily use, resulting in the remission of symptoms after 3 days of medication. This new scenario opens the possibility for clinical and scientific research through randomized studies of the antibiotic tetracycline hydrochloride $500 \mathrm{mg}$, to investigate its action on the viral replication of the new coronavirus.
\end{abstract}

Keywords: Coronavirus; Type 2 diabetes; Tetracycline; Pharmacology

\section{Introduction}

In 2019, the pandemic of the new coronavirus (COVID-19) hit the world and draws attention due to the scope and speed with which it spread [1], becoming one of the great health challenges of the $21^{\text {st }}$ century [2,3]. According to Brito et al (2020) more than 100 countries and territories on the five continents were affected by the impacts on public health and the economy.

The COVID-19 pandemic was faced with unequal responses in different countries and led to dissimilar impacts, between countries like Europe, the United States and Latin America, which were disproportionately affected and highlighting socioeconomic inequalities. Non-pharmacological measures have until now been the only way to try to contain and control the epidemic $[1,4]$.

Successful non-pharmacological interventions include prophylactic measures such as respiratory etiquette, routine cleaning of surfaces and environments, sun exposure of environments, social distance and isolation, which can be the isolation of cases and contacts, until total lockdown [5,6].

After a year of imposing restrictive measures, a new phase began, with vaccination. Once again, contrasts are seen between countries, population and governments $[7,8]$.

\footnotetext{
${ }^{*}$ Corresponding author: Glayson Guimarães Morais Ferreira

Institute of Applied Naturopathy of Belo Horizonte, Mahatman Institute. Alagoas Street, 1314. Belo Horizonte. Minas Gerais. Brazil. 
According to Skeeg et al (2020), due to unsuccessful attempts to search for pharmacological treatment that could be used in the development stages of COVID-19, scientific research has evolved a lot on SARS-CoV-2, with extraordinary and unprecedented progress towards the development of COVID-19 vaccines, but there is still great uncertainty as the pandemic continues to evolve. COVID-19 vaccines are being launched in many countries, but that does not mean that the crisis is close to being resolved. It simply continues to go through a new phase of the pandemic.

In contrast, the pandemic of the new coronavirus / COVID-19 is an invitation to reflection for all humanity, about the innumerable imbalances caused by man, whether from an environmental (physico-chemical-radioactive) or psychosocial (stress) bias.

Such imbalances imply on society the need to reorganize and rethink the future of the community, experiencing harmonious and peaceful coexistence with the different ecosystems that make up the totality of what is understood as our home, the planet Earth $[9,10]$.

According to Silva \& Aleixo (2020) [11] the planet is our home (oikos) and without this harmonious relationship with nature (the ecosystem) we would be doomed to extermination, committing a true ecocide. Thus, the authors affirm that it makes an ethical vision indispensable, guided by a responsible commitment in relation to the future and the right of future generations.

Due to the environmental imbalance, the destabilization of ecosystems, an old one announced as a future possibility and recently presented "global chaos", the COVID-19 pandemic leads us to the questions of "how? through and why?", viruses managed to overcome the barrier of the natural cycles of their ecological niches, starting to seek in human beings the possibility of an ideal host to complete their evolution program [10].

Graf (2020) [12] reports that coronaviruses make up the most diverse family within the order Nidovirales. There are forty-six species described by the International Virus Taxonomy Committee (ICTV) 2 and it is estimated that, in bats, there are more than 3 thousand species of coronavirus. The occurrence of coronaviruses among animals of veterinary importance has been known since 1930, with pathogenic species such as Infectious Bronchitis Virus (IBV) in birds and the swine epidemic diarrhea virus (PEDV). Among humans, the first coronavirus isolate occurred in the 1960s and were associated with mild flu-like conditions. In 2002, with the emergence of SARS, coronaviruses entered the list of potential threats to human health worldwide 3 , demystifying the punctual appearance of the "mutant" bat.

The search for effective prophylaxis as pointed out by Skeeg et al (2020) [4] is just beginning and requires new studies that enable effective preventive and prophylactic treatment. In this context, this article reports on a monitored clinical case study with promising results in patient recovery.

\section{Material and methods}

This study uses a descriptive and observational methodology of the assertive evolution of cases of COVID-19, followed by the Institute of Applied Naturopathy of Belo Horizonte, Instituto Mahatman, in Minas Gerais, Brazil. It is a descriptive, exploratory, non-invasive method, with mediated intervention, which follows in the case report described below:

In February 2021, patient E. N. J., a 42-year-old male patient, approached the medical team with the main complaint of lichenoid pityriasis. In the investigative inquiry, the patient was asked about general data (sex, age, marital status), family history, comorbidities, life habits (if smoker, alcoholic, sedentary); if using medication, origin, or possible cause of the infection. He was not asked about the symptoms of coronavirus infection.

The clinical report includes: ENJ, male, 42 years old, married, obese, type 2 diabetic, reports the use of Glifage XR 500mg (metformin hydrochloride), XIGDUO XR 5mg / 1000mg (dapagliflozin and metformin) Diamicron 30mg (gliclazide), denies alcoholism, denies smoking, is sedentary and informs that he sought dermatological medical care, with lichenoid pityriasis (repetitive event) as his main complaint.

On clinical examination, the lesion was found and tetracycline hydrochloride $500 \mathrm{mg}$ was prescribed every other day for 60 days. There was no change, adequacy or suspension of the medication for daily use.

Still using tetracycline hydrochloride $500 \mathrm{mg}$, in April, she started to show dry cough, fever of $38^{\circ} \mathrm{C}$, runny nose, body pain, tiredness and lack of appetite. As the patient lives in a COVID-14 epidemic municipality, the oral antibiotic dosage was changed to 1 tetracycline hydrochloride tablet $500 \mathrm{mg}$ daily. 
After 72 hours of using the medication, the patient reports that he realized that the symptoms attributed to COVID-19 had "disappeared" (SIC).

In the survey, he also reported that he did not perform any conventional tests that test positive for Sars-Cov-2 viral load, when he had symptoms. It adds, though, that lichenoid pityriasis (main complaint) remained uncontrolled.

On May 15, 2021, a serological test for coronavirus COVID-19 IgM and IgG (Protein S) was requested, with the results, IgM and IgG being reagents.

\section{Results and discussion}

The patient in the case study is diabetic, obese and sedentary, and has a dermatological infection, pityriasis lichenoid (PL), which is a rare inflammatory skin disease, of unknown etiology and has a positive serological test for COVID-19. We will discuss the patient's clinical picture and pharmacological therapy and the possible causes of successful treatment with tetracycline.

Diabetes is one of the comorbidities that makes the body more vulnerable to the development of severe COVID-19. Diabetes does not increase the patient's risk of becoming infected with the new coronavirus, but it does increase the chances of complications resulting from the infection. Diabetes has been associated with increased mortality in patients with COVID-19 [13].

Among diabetic patients, the risk of complications is indirectly related to blood glucose control, that is, the greater the glycemic control, the lower the risk of complications. Obesity-associated hyperglycemia causes a lower immune response, favoring pulmonary complications in COVID-19. Multiple organ failure and thromboembolisms are also serious complications associated with uncontrolled diabetes.

To achieve glycemic control, metformin is a drug used in the treatment of type 2 diabetic patients. Mortality due to COVID-19 of diabetic patients using metformin was 11\%, comparable to that of the general population with COVID-19, as mortality of diabetic patients who did not have metformin in drug therapy was $23 \%$ [13].

The most common symptoms of COVID-19 are hyperthermia, tiredness and dry cough, but some people have nasal congestion, headache, pain, conjunctivitis, sore throat, diarrhea, anosmia, ageusia, rash on the skin or discoloration of the fingers and of the feet. Such symptoms are usually mild and gradual. Most infected people have mild and / or moderate symptoms, so they do not need hospital treatment, however one in six infected people has a worsening of the clinical picture and develops breathing difficulties, usually people belonging to the risk groups mentioned above [14].

To perform the diagnosis of COVID-19 the gold standard test indicated in the presence of symptoms is the RT-PCR. However, when RT-PCR is not performed within 4 to 10 days of the onset of symptoms, the diagnosis of COVID-19 can be made through serological tests. Therefore, serological tests are useful in detecting antibodies to SARS-CoV-2 and help to identify people who have been exposed to the virus or who have recovered from a COVID-19 infection. Studies suggest that most patients develop antibodies only in the second week after the onset of symptoms and that the sensitivity of the tests is greater from the third week onwards [15].

Protein S is used in several serological tests as an immunogenic antigen of the reaction. This is a SARS-Cov-2 fixing protein to the host cell surface via angiotensin-2 converting receptors. In infection, the patient produces antibodies against protein $\mathrm{S}$ that are identified in serological tests [15].

The usual pharmacological treatment for PL includes antibiotics such as tetracycline and erythromycin, topical corticosteroids and immunosuppressants accompanied by non-drug treatments such as phototherapy [16,17]. Tetracyclines are a group of primarily bacteriostatic Antimicrobials, when in therapeutic concentrations. Broad spectrum of action, including gram-positive, aerobic and anaerobic gram-negative bacteria, spirochetes, rickettsiae, mycoplasma, chlamydiae and some protozoa [18].

Tetracyclines, whether natural or semi-synthetic, act by inhibiting bacterial protein synthesis, are bacteriostatic and have a broad spectrum of activity. In the past, tetracyclines have been discredited due to the high prevalence of isolates with acquired resistance. Currently, they are highly active due to the incorporation of new components. Doxycycline is currently the most used tetracycline and is considered an essential drug by the World Health Organization [19]. 
In recent studies, tetracycline has been identified as a potential therapeutic agent for COVID-19 in view of its activity against matrix metalloproteinases and inflammatory cytokines, which are crucial for viral activity [20].

According to Sohdi \& Etiminan (2020) [21] tetracyclines may be able to treat COVID-19 infection by anti-inflammatory activity, including downregulation of the nuclear factor- $K \beta$ pathway, as well as a decrease in the levels of inflammatory cytokines, such as tumor necrosis factor- $\alpha$, interleukin (IL)-1 $\beta$, and IL- 6 regardless of their antibiotic mechanism.

As demonstrated by Yoshikawa et al (2009) [22] Song et al (2020) [23] and reported by Sohdi \& Etiminan (2020) [21], cytokines have a significant increase when the coronavirus picture is associated with severe acute respiratory syndrome (SARS-CoV) is exposed to lung tissue, exacerbating the pathogenesis of the infection.

Recently other authors [24,25] indicated that coronaviruses, regardless of the species of coronavirus, induce the proliferation of mast cells within the respiratory submucosa, which in turn produces inflammatory agents such as histamine and protease, in addition to inflammatory cytokines such as IL-1 and IL-33.

Tetracyclines have an anti-inflammatory action by reducing the levels of inflammatory agents, inducing mast cell apoptosis and activation of protein kinase $\mathrm{C}$. These anti-inflammatory properties are important in the treatment of viral infections such as COVID-19.

They also have potential for treating infections by other viruses, such as human immunodeficiency, West Nile and viral encephalitis [21].

In addition to their anti-inflammatory activity, the potential of tetracyclines to provide a prophylactic benefit in reducing ventilatory support and the length of ICU stay for patients with ARDS (acute respiratory distress syndrome) associated with Sars-Cov-2 infection was evident. Tetracyclines are lipophilic and therefore easily penetrate lung tissues where they inhibit viral replication [26].

Despite the presence of comorbidities that favor complications in COVID-19 (diabetes and obesity), the disease in the patient in this case study does not progress severely. Given the above in relation to the use of tetracyclines in the treatment of COVID-19, the patient's favorable clinical outcome may have occurred because of the use of this drug by the patient.

Considering the therapeutic potential of tetracyclines in the treatment of COVID-19 and the reduction of complications that lead to death, associated with the fact that these drugs are safe therapeutic agents, well tolerated and bioavailable orally, the importance of evaluation in clinical trials of this therapy.

\section{Conclusion}

- The new coronavirus pandemic is plaguing diverse populations worldwide, becoming a health problem of vast extent and difficult to contain.

- Several non-pharmacological measures are being used as tools to try to contain the pandemic, however, the pharmacological treatment recommended by the Ministry of Health has not been showing effective and satisfactory results.

- The patient observed in the description of the case report presented a good clinical evolution with the use of tetracycline hydrochloride $500 \mathrm{mg}$, opening a possibility of investigation of this drug for the treatment of patients with COVID-19.

- Given the above, this new scenario opens the possibility for clinical and scientific research through randomized studies of the antibiotic tetracycline hydrochloride $500 \mathrm{mg}$, to investigate its action on the viral replication of the new coronavirus.

\section{Compliance with ethical standards}

\section{Acknowledgments}

The authors appreciate the Institute of Applied Naturopathy of Belo Horizonte, Mahatman Institute. 


\section{Disclosure of conflict of interest}

The authors declare that there is no conflict of interests regarding the publication of this paper.

\section{Statement of informed consent}

The patient was included after an interview to explain the nature of the work and after signing written consent forms.

\section{References}

[1] Souza, D de 0. The COVID-19 pandemic beyond the Health Sciences: reflections on its social determination. Scienc. Health Col. June 2020; 25(1): 2469-77.

[2] Brito SBP, Braga IO, Cunha CC, Palácio MAV, Takenami I. COVID-19 pandemic: the biggest challenge for the 21st century. Vigil. Sanit. Debate. 2020; 8(2): 54-63.

[3] Schmidt B, Crepaldi MA, Bolze SDA, Neiva-Silva L, Demenech LM. Mental health and phychological interventions in the face of the new coronavirus pandemic (COVID-19). Estud. Psicol. 2020; 37.

[4] Skegg D, Gluckman P, Boulton G, Hackmann H, Karim SSA, Piot P, Woopen C. Future scenarios for the COVID-19 pandemic. The Lancet. 27 of February of. 2021; 397(10276): 777- 8.

[5] Malta DC, Swarcwald CL, Barros MBA, Gomes CS, Machado IE, Souza Júnior PRB, Romero DE, Lima MG, Damacena GN, Pina MF, Freitas MIF, Werneck AO, Silva DRP, Azevedo LO, Gracie R. The COVID-19 Pandemic and changes in adult Brazilian lifestyle: a cross-sectional study, 2020. Epidemiol. Serv. Health; 2020: 1-13.

[6] Garcia LP \& Duarte E. Non-pharmacological interventions to fight the COVID-19 epidemic in Brazil. Epidemiology and Health Services. May 2020; 29(2).

[7] Martins WA, Oliveira GMM, Brandão AA, Mourilhe-Rocha R, Mesquita ET, Saraiva JFK, Bacal F, Lopes MACQ. Cardiopathy vaccination against COVID-19: The reasons of the priority. Brazilian Archives of Cardiology. 2021; 116(2).

[8] Simas L, Larouze B, Diuana V, Sánchez A. For an equitable vaccination strategy for the deprived population against COVID-19. Public Health Notebook. 2021; 37(4).

[9] Davim A, Silva L T, Vieira P. Environmental Enrichment as a Strategy to Confront Social Isolation Under the COVID-10 Pandemic. Frontiers in Behavioral Neuroscience. 2021 January; 14: 1-7. https://doi.org/10.3389/fnbeh.2020.564184

[10] Mattos JRA \& Separavich MA. Reflections on the pandemic in the light of the Encyclical Laudato Si. Reflection. $2020 ; 45$

[11] Silva 00 \& Aleixo D. On the ecological crisis and its relationship with the Coronavirus pandemic (COVID-19): a reflection in the light of the responsibility ethics project in Hans Jonas. Philosophical Opinion Magazine. 2020 December; 11(3): 1-20. https://doi.org/10.36592/opiniaofilosofica.v11.1001

[12] Phan T. Genetic diversity and evolution of SARS-CoV-2. Infect Genet Evol. 2020 Jul; 81(1): 104260. doi: 10.1016/j.meegid.2020.104260.

[13] Gupta R, Hussain A, Misra A. Diabetes and COVID-19: evidence, current status and unanswered research questions. Eur J Clin Nutr. 2020 Jun; 74(6): 868-870. doi: 10.1038/s41430-020-0652-1.

[14] Pan American Health Organization (PAHO). How the virus responsible for COVID-19 spreads. Disponível em: https://www.paho.org/pt/COVID19\#contagio. Acesso em 25 de maio de 2021.

[15] Dramé M, Teguo MT, Proye E, Hequet F, Hentzien M, Kanagaratum L, Godaert L. O RT-PCR be considered a gold standard in the diagnosis of COVID-19? J Med Virol. 2020 Nov; 92(11): 2312-2313. doi: 10.1002/jmv.25996.

[16] Bowers S, Warshaw EM. Pityriasis lichenoides and its subtypes. J Am Acad Dermatol. 2006; 55: 557-572.

[17] Chen Y, Zhao M, Xiang X, Wang Z, Xu Z, Ma L. Oral erythromycin in pityriasis lichenoides chronica and pityriasis lichenoides et varioliformis acuta. Dermatologic Therapy. May 2020; 33(3): e13311.

[18] ANVISA. Brazi, Ministry of Health. National Health Surveillance Agency. Antimicrobials: Theoretical bases and clinical uses. Tetracyclines. Normative Instruction $n^{\circ} 86,12$ march of 2021. 
[19] Vicente D, Pérez-Trallero E. Tetraciclinas, sulfamidas y metronidazol [Tetracyclines, sulfonamides, and metronidazole]. Enferm Infecc Microbiol Clin. Feb 2010; 28(2): 122-30.

[20] Tan SHS, Hong CC, Saha S, Murphy D, Hui JH. Medications in COVID-19 patients: summarizing the current literature from an orthopaedic perspective. International Orthopaedics (SICOT). Aug 2020; 44(8): 1599-603.

[21] Sodhi M \& Etminan M. Therapeutic Potential for Tetracyclines in the Treatment of COVID-19. Pharmacoterapy. 2020 May; 40(5): 487-488. doi: 10.1002/phar.2395.

[22] Yoshikawa T, Hill T, Li K, Peters CJ, Tseng CT. Severe acute respiratory syndrome (SARS) coronavirus-induced lung epithelial cytokines exacerbate SARS pathogenesis by modulating intrinsic functions of monocyte-derived macrophages and dendritic cells. J Virol. 2009; 83(7): 3039-48.

[23] Song P, Lim W, Xie J, Hou Y, You C. Cytokine storm induced by SARS-CoV-2. Clinica Chimica Acta. outubro de. 2020; 509: 280-7.

[24] Kritas SK, Ronconi G, Caraffa AL, Gallenga CE, Ross R. And Conti. P. Mast Cells contribute To Coronavirus-Induced Inflammation: New Anti-Inflammatory Strategy. Journal of Biological Regulators \& Homeostatic Agents. February 2020; 33(6): 9-14.

[25] Kempuraj D, Selvakumar GP, Ahmed ME, Raikwar SP, Thangavel R, Khan A, Zaheer SA, Iyer SS, Burton C, James D, Zaheer A. COVID-19, Mast Cells, Cytokine Storm, Psychological Stress, and Neuroinflammation. The Neuroscientist. October 2020; 26(5-6): 402-414.

[26] Al-kuraishy HM, Al-Gareeb AI, Alqarni M, Cruz-Martins N, Batiha GES. Pleiotropic Effects of Tetracyclines in the Management of COVID-19: Emerging Perspectives. Front. Pharmacol. 2020 April; 12: 1-7. https://doi.org/10.3389/fphar.2021.642822 